\title{
Geen vereenzelviging van moeder- en dochtermaatschappij ten aanzien van aanbestedingsplicht
}

\author{
Mr. E.E. Zeelenberg*
}

De zaak heeft betrekking op een dochtermaatschappij van de Litouwse (staats)Spoorwegen. Deze dochtermaatschappij draait 90 procent van haar omzet op opdrachten van de Litouwse Spoorwegen. De vraag rijst of deze dochtermaatschappij een aanbestedende dienst is. Het Hof van Justitie oordeelt dat daartoe moet worden getoetst aan de criteria voor kwalificatie als publiekrechtelijke instelling. De advocaat-generaal was overigens een andere mening toegedaan.

Hv7 5 oktober 2017, zaak C-567/15, LitSpecMet UAB/

Vilniaus lokomotyou remonto depas UAB, ECLI:EU:C:

2017:736 en Conclusie A-G Campos Sánchez-Bordona

27 april 2017, zaak C-567/15, LitSpecMet UAB/Vilniaus lokomotyou remonto depas UAB, ECLI:EU:C: 2017:319

\section{Casus en prejudiciële vragen}

Vilniaus lokomotyvu remonto depas UAB (hierna: VLRD) is een volle dochtermaatschappij van het staatsbedrijf der Litouwse spoorwegen (hierna: LG). VLRD fabriceert en onderhoudt locomotieven en wagons. Ten tijde van de feiten was het Litouws spoorwegbedrijf de belangrijkste klant van VLRD, met orders die goed waren voor bijna 90 procent van haar omzet.

In 2013 schreef VLRD een vereenvoudigde (niet-Europese) openbare aanbesteding uit voor de levering van staven ferrometaal. LitSpecMet UAB diende een offerte in en haalde een deel van de opdracht binnen. Niettemin vorderde zij in rechte nietigverklaring van de aanbesteding en heraanbesteding van de opdracht volgens de regels voor het plaatsen van overheidsopdrachten. ${ }^{1}$ Naar de mening van LitSpecMet kwalificeert VLRD als een aanbestedende dienst en diende deze dus aan te besteden volgens de daarvoor geldende regels. In eerste aanleg en hoger beroep ving LitSpecMet bot; beide rechterlijke instanties waren van oordeel dat VLRD niet voldeed aan het vereiste dat haar activiteiten gericht moeten zijn op het dienen van algemene belangen die niet van industriële of commerciële aard zijn. Om die reden kon VLRD niet worden aangemerkt als aanbestedende dienst. De hoogste Litouwse rechter vernietigde het arrest van de appèlrechter echter, omdat hij van oordeel was dat niet naar behoren was ingegaan op de omstandigheden rond de oprichting van VLRD, de bijzondere aard van haar activiteit en haar betrekkingen met haar moedermaatschappij, LG. Naar het oordeel van de hoogste Litouwse rechter hadden de beide lagere rechters voor hun conclusie dat VLRD geen aanbestedende dienst was, te veel belang gehecht aan haar vennootschapsvorm (een handelsvennootschap). De lagere rechters hadden daarbij nagelaten de specifieke aard te onderzoeken van de economische activiteiten die door VLRD werden verricht, met name wat de intensiteit van de concurrentie in de economische sector betreft waarin VLRD actief is.

De zaak werd terugverwezen naar de feitenrechter, die het Hof van Justitie prejudiciële vragen voorlegt. Deze vragen komen erop neer dat de rechter wil weten of artikel 1 lid 9 tweede alinea van Richtlijn 2004/18/EG zo moet worden uitgelegd dat een onderneming die enerzijds volledig in handen is van een aanbestedende dienst die voorziet in behoeften van algemeen belang en anderzijds zowel transacties voor die aanbestedende dienst als transacties op een concurrerende markt verricht, kan 
worden aangemerkt als 'publiekrechtelijke instelling' in de zin van die bepaling. Indien dat het geval is, wil de verwijzende rechter vervolgens weten of daarbij nog van belang is dat de waarde van de inhousetransacties in de toekomst mogelijk minder dan 90 procent of niet meer het grootste gedeelte van de totale omzet van de dochtermaatschappij uitmaakt.

\section{Het oordeel van het Hof van Justitie}

Om te kwalificeren als publiekrechtelijke instelling moet zijn voldaan aan de volgende drie cumulatieve criteria: ${ }^{2}$

1. de entiteit moet zijn opgericht met het specifieke doel te voorzien in behoeften van algemeen belang, niet zijnde van industriële of commerciële aard; en

2. de entiteit heeft rechtspersoonlijkheid; en

3. er is sprake van overwegende overheidsbemoeienis in de vorm van een van de volgende alternatieve mogelijkheden:

- overwegende overheidsfinanciering, of;

- toezicht vooraf op de bedrijfsvoering, waaronder besluitvorming tot plaatsing van overheidsopdrachten, of;

- benoemingsrechten: benoeming van meer dan de helft van de leden van 'de directie, de raad van bestuur of de raad van toezicht' worden aangewezen door - kort gezegd - de overheid.

Vaststaat dat de activiteiten van LG, waaronder het aanbieden van openbaar vervoer, activiteiten zijn ter vervulling van behoeften van algemeen belang en dat deze moedermaatschappij moet worden aangemerkt als een 'publiekrechtelijke instelling' en dus als een 'aanbestedende dienst'. De vraag is echter of ook haar 100 procent dochter VLRD moet worden aangemerkt als een publiekrechtelijke instelling. Het Hof van Justitie stelt hierbij voorop dat een onderneming niet reeds als een aanbestedende dienst kan worden beschouwd enkel en alleen omdat zij door een aanbestedende dienst is opgericht of omdat haar activiteiten worden gefinancierd met financiële middelen afkomstig uit de door een aanbestedende dienst verrichte activiteiten. ${ }^{3}$ Kortom: er mag op dit punt geen vereenzelviging van moeder- en dochtermaatschappij plaatsvinden. Onderzocht moet worden of VLRD zelf (ook) aan de drie cumulatieve criteria voldoet.

Het Hof van Justitie constateert dat VLRD lijkt te voldoen aan het tweede en derde criterium voor kwalificatie

2. Zie art. 1 lid 9 tweede alinea van de ten tijde van de feiten van deze zaak toepasselijke Richtlijn 2004/18/EG. Deze criteria zijn identiek aan de criteria van art. 2 lid 4 van de huidige aanbestedingsrichtlijn (Richtlijn 2014/24/EU).

3. HvJ 5 oktober 2017, zaak C-567/15, LitSpecMet UAB/Vilniaus lokomotyvu remonto depas UAB (hierna: LitSpecMet), ECLI:EU:C:2017:736, JAAN 2017/248 m.nt. P. Heijnsbroek, punt 34, onder verwijzing naar HvJ 15 januari 1998, zaak C-44/96, Mannesmann Anlagenbau Austria e.a., ECLI:EU:C:1998:4, punt 39. als publiekrechtelijke instelling. Vaststaat dat VLRD rechtspersoonlijkheid heeft. Verder heeft de verwijzende rechter vastgesteld dat VLRD een volle dochtermaatschappij is van LG en dat zij onderworpen is aan 'toezicht' door LG. ${ }^{4}$ De enige openstaande vraag is dus of VLRD een instelling is die 'is opgericht met het specifieke doel te voorzien in behoeften van algemeen belang die niet van industriële of commerciële aard zijn'.

Het Hof van Justitie maakt duidelijk dat dit criterium uit twee toetsonderdelen bestaat. Eerst is de vraag aan de orde of de betreffende entiteit (in casu VLRD) is opgericht 'met het specifieke doel te voorzien in behoeften van algemeen belang' en of haar activiteiten werkelijk in dergelijke behoeften voorzien. Als dat het geval is, moet vervolgens worden onderzocht of die behoeften al dan niet van industriële of commerciële aard zijn. ${ }^{5}$

Ten aanzien van de eerste vraag - te weten of VLRD is opgericht met het specifieke doel om te voorzien in behoeften van algemeen belang - merkt het Hof van Justitie op dat VLRD is opgericht om te voorzien in de behoeften van haar moedermaatschappij LG. VLRD levert goederen en verricht diensten die haar moedermaatschappij in staat stellen haar passagiers- en vrachtvervoer te verzekeren. De behoeften met de vervulling waarvan VLRD is belast zijn daarmee een noodzakelijke voorwaarde voor de uitoefening door LG van haar activiteiten van algemeen belang. De verwijzende rechter dient echter nog na te gaan of dit echt zo is. Indien dat het geval is, voorziet ook VLRD in behoeften van algemeen belang als bedoeld in dit criterium.

Dat VLRD niet enkel en alleen activiteiten ter vervulling van behoeften van algemeen belang verricht voor haar moedermaatschappij LG, maar ook andere activiteiten, waarmee zij winst nastreeft, is in dit verband niet relevant. Het wettelijke criterium vereist namelijk niet dat een entiteit uitsluitend de voorziening in specifieke behoeften van algemeen belang tot taak moet hebben. Volgens vaste jurisprudentie van het Hof van Justitie is het daarom niet van belang dat de betrokken entiteit naast de activiteiten ter vervulling van behoeften van algemeen belang ook activiteiten met een winstoogmerk verricht op een concurrerende markt. Zelfs het feit dat de voorziening in de behoeften van algemeen belang maar een relatief klein deel uitmaakt van de activiteiten die een entiteit verricht, is volgens deze rechtspraak irrelevant, zolang de entiteit zich blijft kwijten van haar specifieke taken van algemeen belang. ${ }^{6}$

Vervolgens dient te worden beoordeeld of die behoeften van algemeen belang waarin VLRD (voor haar moeder) voorziet al dan niet van industriële of commerciële aard zijn.

Volgens vaste rechtspraak van het Hof van Justitie moet bij deze beoordeling worden gelet op alle relevante juridische en feitelijke elementen, zoals de omstandigheden

4. Zie LitSpecMet, punt 32

5. Zie LitSpecMet, punt 34, onder verwijzing naar HvJ 22 mei 2003, zaak C-18-01, Korhonen e.a., ECLI:EU:C:2003:300, punt 40.

6. Zie in die zin o.a. HvJ 15 januari 1998, zaak C-44/96, Mannesmann Anlagenbau Austria e.a., ECLI:EU:C:1998:4, punt 25, en HvJ 10 april 2008, zaak C-393/06, Ing. Aigner, ECLI:EU:C:2008:213, punt 47. 
waaronder de betrokken instelling is opgericht en de voorwaarden waaronder zij werkzaam is, met inbegrip van met name het ontbreken van mededinging op de markt, het niet hoofdzakelijk hebben van een winstoogmerk, het niet dragen van de met die activiteit verbonden risico's alsook het financieren van de betrokken activiteit met openbare middelen. ${ }^{7}$ Het is immers weinig waarschijnlijk dat, indien een entiteit onder normale marktvoorwaarden actief is, winst nastreeft en de met de uitoefening van haar activiteit verbonden verliezen draagt, de behoeften waarin zij wil voorzien van andere dan industriële of commerciële aard zijn. ${ }^{8}$ Hoofdregel is dus dat een organisatie die onder normale marktomstandigheden actief is, winst nastreeft en de met de uitoefening van haar activiteit verbonden verliezen draagt, in de regel níet als publiekrechtelijke instelling kan worden aangemerkt.

Het Hof van Justitie oordeelt dat het de taak van de verwijzende rechter is om op basis van alle juridische en feitelijke elementen van het geval na te gaan of VLRD ten tijde van de gunning van de in het hoofdgeding aan de orde zijnde opdracht haar activiteiten ter vervulling van behoeften van algemeen belang verrichtte in een situatie van concurrentie, en met name of VLRD zich in de concrete omstandigheden kon laten leiden door andere dan economische overwegingen.

De mogelijkheid die de verwijzende rechter oppert in zijn verwijzingsbeslissing, dat de inhousetransacties met het Litouws spoorwegbedrijf in de toekomst een kleiner gedeelte van de omzet van VLRD gaan uitmaken, mist volgens het Hof van Justitie relevantie in dit verband. De rechter dient na te gaan hoe de situatie van die onderneming was op het tijdstip waarop de opdracht in kwestie is gegund en dient daarbij geen hypothetische toekomstige situaties te betrekken.

\section{Commentaar}

Geen vereenzelviging van moeder en dochter

Het Hof van Justitie koppelt de vraag of dochtermaatschappij VLRD een aanbestedende dienst is duidelijk los van het feit dat VLRD het leeuwendeel van haar opdrachten ontvangt van haar moeder via de inbestedingsuitzondering. ${ }^{9}$ Dogmatisch is dit helemaal correct. Voor een beroep op de inbestedingsuitzondering is het namelijk niet noodzakelijk dat de entiteit waaraan de opdrachten worden gegund zelf ook kwalificeert als een

7. Zie o.a. HvJ 27 februari 2003, zaak C-373/00, Truley, punt 66, HvJ 22 mei 2003, zaak C-18/01, Korhonen, ECLI:EU:C:2003:300, punten 48 en 59 en HvJ 16 oktober 2003, zaak C-283/00, Commissie/Spanje, ECLI:EU:C:2003:544, punten 81 en 82.

8. Zie Korhonen, punt 51, Commissie/Spanje, punt 82 en LitSpecMet, punt 44.

9. In de vorm van een publiekrechtelijke instelling. aanbestedende dienst. ${ }^{10}$ Voldoende is (1) dat de opdrachtverlenende aanbestedende dienst - in dit geval LG - toezicht houdt op de opdrachtnemer 'als op eigen diensten', (2) de opdrachtnemer het merendeel van haar activiteiten - zijnde minimaal 80 procent - verricht voor de aanbestedende dienst(en) die toezicht op haar houdt (houden) en (3) er geen directe participatie van privékapitaal is in de opdrachtnemer. ${ }^{11}$ De inbestedingsuitzondering ziet ook alleen op opdrachten die worden verleend in de relatie tussen, in dit geval, moedermaatschappij LG en dochtermaatschappij VLRD en niet op opdrachten die VLRD (vervolgens) aan derden wenst te vergeven. ${ }^{12}$ De vraag of voor die opdrachten van VLRD aan derden een aanbestedingsplicht geldt, hangt af van de vraag of VLRD zelf (ook) kwalificeert als aanbestedende dienst. Het Hof van Justitie maakt duidelijk dat VLRD daartoe niet mag worden vereenzelvigd met haar moeder, maar zelf aan alle drie de cumulatieve criteria van het begrip publiekrechtelijke instelling dient te voldoen. Het lijkt er volgens het Hof van Justitie op dat VLRD aan deze criteria voldoet, maar de nationale rechter dient dit nog na te gaan. ${ }^{13}$

\section{Gevaar voor ontduiking van de}

aanbestedingsregels?

Opvallend is dat advocaat-generaal Campos SánchezBordona de toets of VLRD kwalificeert als een publiekrechtelijke instelling niet aangewezen vindt. De advocaat-generaal hecht in zijn conclusie bij deze zaak ${ }^{14}$ meer waarde aan het feit dat de VLRD zelf via een inhouseuitzondering haar opdrachten gegund krijgt. De toepassing van de inhouse-uitzondering mag dan gerechtvaardigd zijn, de dochtermaatschappij kan zich (juist) voor externe transacties die noodzakelijk zijn om de aan haar opgedragen taken te vervullen volgens de advocaatgeneraal niet onttrekken aan de aanbestedingsrichtlijnen (voor zover de waarde daarvan de toepassingsdrempel overschrijdt). Anders zou LG de werking van de aanbestedingsrichtlijnen kunnen ontlopen door haar activitei-

10. Zie HvJ 18 november 1999, zaak C-107-98, Teckal, ECLI:EU:C: 1999:562, punt 51 en HvJ 11 januari 2015, zaak C-26/03, Stadt Halle, ECLI:EU:C:2005:5, punten 44 en 47 . Bij de alleenrechtuitzondering is daarentegen wel een vereiste dat de opdrachtnemer kwalificeert als aanbestedende dienst, zie art. 2.24 sub a Aanbestedingswet 2012. Van die uitzondering wordt in deze zaak echter geen gebruik gemaakt.

11. Zie art. 12 leden 1 en 3 Richtlijn 2014/24/EU en art. 2.24a lid 1 en 2.24b lid 1 Aanbestedingswet 2012. Opmerking verdient dat Richtlijn 2014/24/EU (en de art. 2.24a en 2.24b van de Aanbestedingswet) nog niet van kracht was ten tijde van de feiten van onderhavig arrest, maar in art. 12 van deze richtlijn zijn de criteria zoals die voorheen golden op basis van vaste jurisprudentie van het Hof van Justitie gecodificeerd (o.a. HvJ 18 november 1999, zaak C-107-98, Teckal, HvJ 13 oktober 2005, zaak C-458/03, Parking Brixen, ECLI:EU:C:2005:605 en HvJ 11 mei 2006, zaak C-340/04, Carbotermo, ECLI:EU:C:2006:308).

12. Ook om die reden is naar mijn mening de mogelijkheid dat de waarde van de inhousetransacties in de toekomst mogelijk minder dan 90 procent van de omzet van VLRD gaat uitmaken, niet relevant. Indien dat het geval is, zegt dat mogelijk alleen wat over de vraag of LG nog steeds met een beroep op de inbestedingsuitzondering opdrachten zonder aanbesteding kan gunnen aan VLRD, maar dit zegt verder niets over de opdrachten die VLRD zelf aan derden wenst te vergeven.

13. LitSpecMet, punt 34

14. Conclusie A-G Campos Sánchez-Bordona 27 april 2017 inzake LitSpecMet, ECLI:EU:C:2017:319. 
ten eenvoudigweg te reorganiseren door middel van de oprichting van een dochtermaatschappij. Om die reden hoeft volgens de advocaat-generaal ten aanzien van VLRD niet te worden nagegaan of sprake is van een publiekrechtelijke instelling. Een onderneming die zodanige materiële en functionele banden onderhoudt met een aanbestedende dienst dat toepassing van de inhouse-uitzondering gerechtvaardigd is, is volgens de advocaat-generaal aan die richtlijnen onderworpen wanneer zij opdrachten plaatst ter vervulling van de taak waarmee zij door de aanbestedende dienst is belast. ${ }^{15}$

Daar waar het Hof van Justitie expliciet aangeeft dat VLRD niet mag worden vereenzelvigd met haar moeder, ging de advocaat-generaal dus juist wel uit van de vereenzelviging van moeder- en dochtermaatschappij. Op basis daarvan geldt er, volgens de advocaat-generaal, voor VLRD sowieso een aanbestedingsverplichting ongeacht of zij zelf kwalificeert als aanbestedende dienst of niet - ten aanzien van de taken die VLRD opgedragen heeft gekregen van LG, maar die VLRD niet zelf uitvoert maar door derden wil laten uitvoeren. Via die vereenzelviging beoogt de advocaat-generaal te voorkomen dat LG haar aanbestedingsplicht kan ontduiken. Dat ontduikingsrisico ziet op de situatie dat een moedermaatschappij taken waarvoor op haarzelf een aanbestedingsverplichting zou rusten indien zij deze aan derden zou willen opdragen, via de inbestedingsuitzondering onderbrengt bij een dochtermaatschappij, waarna die dochtermaatschappij de betreffende taken niet zelf uitvoert, maar deze alsnog uitbesteedt aan derden en daarbij niet aanbestedingsplichtig zou zijn omdat de dochtermaatschappij niet kwalificeert als aanbestedende dienst.

In de Nederlandse rechtspraak is die vereenzelviging tussen moeder- en dochtermaatschappij om dezelfde reden ook al eens aangenomen. In een arrest van 25 oktober $2016^{16}$ over de exploitatie van het reclamearsenaal van het Rotterdamse openbaarvervoersbedrijf Rotterdamse Elektrisch Tram N.V. (hierna: RET), oordeelde het Hof Den Haag dat zelfs als dochtermaatschappij RET Services b.v. niet als publiekrechtelijke instelling kon worden beschouwd, zij ten aanzien van de toepassing van de aanbestedingsregels moest worden vereenzelvigd met haar moeder RET. Zou daarover

15. De A-G maakt hierbij nog een onderscheid tussen enerzijds de 'hoofdactiviteiten' die VLRD voor LG verricht als gevolg van de inhouseopdrachten en anderzijds de marginale andere activiteiten die VLRD verricht. Voor de hoofdactiviteiten zou volgens de A-G moeten worden uitgegaan van een vereenzelviging tussen moeder en dochter en ten aanzien van de marginale andere activiteiten zou nog wel moeten worden getoetst aan de criteria van het begrip publiekrechtelijke instelling. Een dergelijke onderverdeling waardoor een entiteit gedeeltelijk wel en gedeeltelijk niet aanbestedingsplichtig is, lijkt mij echter niet wenselijk. Dit zou voor veel onduidelijkheid zorgen en verhoudt zich naar mijn mening ook niet tot de hierna nog te bespreken infectietheorie op grond waarvan een entiteit wier activiteiten slechts voor een relatief klein deel voorzien in behoeften van algemeen belang aanbestedingsplichtig is, óók voor opdrachten die geen verband houden met de activiteiten van algemeen belang.

16. Hof Den Haag 25 oktober 2016, ECLI:NL:GHDHA:2016:3169, JAAN 2016/47 m.nt. M.J.J.M. Essers en TBR 2017/62 m.nt. A.J. van Heeswijck. anders worden gedacht, dan zou een aanbestedende dienst zich eenvoudig aan de aanbestedingsregels kunnen onttrekken door bepaalde activiteiten in een aparte rechtspersoon onder te brengen, aldus het Hof Den Haag.

Verhouding tot andere Europese jurisprudentie Het mogelijke gevaar van ontduiking van de aanbestedingsverplichtingen via een dochtermaatschappij was voor zowel het Hof Den Haag als advocaat-generaal Campos Sánchez-Bordona dus aanleiding om uit te gaan van een functionele toepassing van de aanbestedingsregels op een dochtermaatschappij van een aanbestedende dienst. Uit vaste jurisprudentie van het Hof van Justitie volgt dat er aan het begrip publiekrechtelijke instelling ook een functionele uitleg moet worden gegeven. ${ }^{17}$ Daarvoor dient te worden gekeken naar het doel van de EU-aanbestedingsrichtlijnen. Dit doel is om zowel het risico uit te sluiten dat aanbestedende diensten bij het plaatsen van opdrachten de voorkeur geven aan nationale inschrijvers of gegadigden, als de mogelijkheid uit te sluiten dat een aanbestedende dienst zich door andere dan economische overwegingen laat leiden. ${ }^{18}$ In een andere context heeft het Hof van Justitie ook al eens uitgesproken dat ontduikingsgedrag door aanbestedende diensten via een andere entiteit niet toelaatbaar is. Zo oordeelde het Hof van Justitie in het $S_{c a l a-a r r e s t}{ }^{19}$ dat het enkele feit dat een aanbestedende dienst wettelijk gebonden is aan één bepaalde contractspartij, die aanbestedende dienst nog niet ontslaat van haar aanbestedingsverplichting. Aan die verplichting diende alsnog te worden voldaan door die aanbestedingsverplichting contractueel door te leggen aan de contractspartij. Tegen deze achtergrond verbaast het enigzins dat het Hof van Justitie in onderhavig arrest in het geheel niet ingaat op de ontduikingsmogelijkheid waar de advocaat-generaal in de conclusie op wijst.

Niet vereenzelvigen versus infectietheorie Natuurlijk verschilt onderhavige casus duidelijk van de casus van het Scala-arrest, doordat daar sprake was van gunning van de opdracht aan een derde, particuliere, partij, terwijl in onderhavige zaak LG de opdrachten gunt aan haar dochtermaatschappij. Voor die gunning van moeder- aan dochtermaatschappij geldt geen aanbestedingsverplichting vanwege de toepasselijkheid van de inbestedingsuitzondering. Maar het risico dat een moedermaatschappij via het onderbrengen van activiteiten in haar dochtermaatschappij haar eigen aanbestedingsplicht ontduikt, is niet ondenkbaar. Dit risico bestaat met name indien de moedermaatschappij een aanbeste-

17. Zie o.a. HvJ 17 december 1998, zaak C-353/96, Commissie/lerland, ECLI:EU:C:1998:611, punt 36, HvJ 1 februari 2001, zaak C-237/99, Commissie/Frankrijk, ECLI:EU:C:2001:70, punten 42 en 43, en HvJ 13 januari 2005, zaak C-84/03, Commissie/Spanje, ECLI:EU:C:2005:14, punten 27 en 28

18. Zie o.a. HvJ 10 november 1998, zaak C-360/96, BFI/Arnhem, ECLI:EU:C:1998:525 en HvJ 3 oktober 2000, zaak C-380/98, Univesity of Cambridge, ECLI:EU:C:2000:529.

19. HvJ 12 juli 2001, zaak C-399/98, Scala, ECLI:EU:C:2001:401, Jur. 2001, p. I-05409. 
dende dienst is in de vorm van een publiekrechtelijke instelling. Aangezien een dergelijke aanbestedende dienst, zoals het Hof van Justitie nog eens herhaalt in onderhavig arrest, ${ }^{20}$ naast activiteiten ter vervulling van behoeften van algemeen belang ook commerciële activiteiten kan verrichten, zou die moedermaatschappij ervoor kunnen kiezen een dochtermaatschappij op te richten die zij zo vorm geeft dat daarin enkel alle commerciële activiteiten worden geplaatst. Indien dat het geval is en de dochtermaatschappij onder normale marktomstandigheden actief is, winst nastreeft en zelf de verliezen draagt van haar activiteiten, zal die dochtermaatschappij niet kwalificeren als aanbestedende dienst. De dochtermaatschappij voldoet dan immers (juist) niet aan de voorwaarde dat sprake moet zijn van het voorzien in behoeften van algemeen belang, niet zijnde van industriële of commerciële aard. De dochtermaatschappij hoeft dan haar eventuele opdrachten aan derden niet aan te besteden, terwijl hiervoor op de moedermaatschappij wel een aanbestedingsverplichting zou rusten, indien de moedermaatschappij die activiteiten aan zichzelf gehouden had. In het Aigner-arrest ${ }^{21}$ oordeelde het Hof van Justitie immers dat een aanbestedende dienst wiens activiteiten slechts voor een relatief klein deel voorzien in behoeften van algemeen belang aanbestedingsplichtig is, óók voor opdrachten die geen verband houden met de activiteiten van algemeen belang. ${ }^{22}$ Dit wordt ook wel de infectietheorie genoemd. Aan die infectietheorie zou dus kunnen worden ontkomen door de activiteiten die geen verband houden met de activiteiten van algemeen belang niet zelf uit te voeren, maar hiervoor een dochtermaatschappij op te richten. Aan de andere kant heeft het Hof van Justitie in het Mannesmann-arrest ${ }^{23}$ al geoordeeld dat de infectietheorie niet zover gaat dat een heel concern hierdoor automatisch 'besmet raakt' als aanbestedende dienst. Het enkele feit dat een entiteit is opgericht door een aanbestedende dienst of van een aanbestedende dienst financiële middelen ontvangt, maakt nog niet dat die entiteit kwalificeert als publiekrechtelijke instelling en dus als aanbestedende dienst. Binnen een concern dient per entiteit te worden nagegaan of deze voldoet aan de drie cumulatieve voorwaarden om te kwalificeren als publiekrechtelijke instelling. Daarmee heeft het Hof van Justitie in feite in 1998 al de mogelijkheid erkend om commerciële activiteiten te onttrekken aan de werking van de EU-aanbestedingsrichtlijnen door deze in een specifieke (commerciële) dochter onder te brengen. Kennelijk ziet het Hof van Justitie geen aanleiding om deze mogelijkheid te blokkeren door thans van lijn te veranderen.
Vereenzelviging in casu niet nodig voor

aanbestedingsverplichting VLRD

Maar wellicht is het antwoord op de vraag waarom het Hof van Justitie in onderhavig arrest in het geheel niet ingaat op het ontduikingsrisico waar de advocaat-generaal op wees nog wel eenvoudiger. Ten aanzien van LG en VLRD lijkt dit ontduikingsrisico zich namelijk niet voor te doen. Weliswaar stelt het Hof van Justitie vast dat LG een aanbestedende dienst is in de vorm van een publiekrechtelijke instelling, ${ }^{24}$ maar het Hof van Justitie stelt daarbij tevens vast dat de activiteiten die LG verricht activiteiten zijn ter vervulling van behoeften van algemeen belang. Verder concludeert het Hof van Justitie dat dochter VLRD kennelijk is opgericht met het specifieke doel te voorzien in behoeften van algemeen belang, niet zijnde van commerciële aard, namelijk het voorzien in taken die ertoe strekken haar moedermaatschappij LG in staat te stellen haar behoeften van algemeen belang - het passagiers- en vrachtvervoer - te verzekeren. Daarmee voorziet ook VLRD in behoeften van algemeen belang. ${ }^{25}$ In elk geval is het duidelijk niet zo dat LG in VLRD enkel activiteiten heeft ondergebracht die geen verband houden met activiteiten van algemeen belang. Daarmee doet het hiervoor omschreven ontduikingsrisico zich niet voor. Vanwege het feit dat VLRD voornamelijk voorziet in behoeften van algemeen belang, niet zijnde van commerciële aard, kwalificeert zij zeer waarschijnlijk zelf ook als aanbestedende dienst. Dat betekent dat er op haar een eigen aanbestedingsplicht rust en er via haar dus geen aanbestedingsverplichting verloren gaat. Anders gezegd: er is in casu geen vereenzelviging van moeder en dochter nodig om tot een op VLRD rustende aanbestedingsverplichting te kunnen concluderen. Zoals hiervoor uiteengezet is het voor kwalificatie als publiekrechtelijke instelling (en dus als aanbestedende dienst) niet vereist dat een entiteit uitsluitend de voorziening in specifieke behoeften van algemeen belang tot taak moet hebben. De kwalificatie als publiekrechtelijke instelling blijft zelfs in stand indien het voorzien in behoeften van algemeen belang maar een relatief klein deel van de activiteiten van de entiteit uitmaakt. Om die reden is de tweede vraag van de verwijzende rechter naar de consequentie van het mogelijk in de toekomst aanzienlijk afnemen van de taken die VLRD voor LG uitvoert, niet relevant. Zolang VLRD een (relatief klein) deel van haar taken blijft uitvoeren voor LG, blijft zij kwalificeren als publiekrechtelijke instelling en dus als aanbestedende dienst.

\section{Conclusie}

Onderhavig arrest makt duidelijk dat er niet zonder meer van uit mag worden gegaan dat een dochtermaatschappij van een aanbestedende dienst, die op basis van

24. Zie LitSpecMet, punt 27

25. Zij het dat dit door de verwijzende rechter nog wel nader getoetst dient te worden, zo oordeelt het Hof van Justitie in punt 39 
de inbestedingsuitzondering opdrachten ontvangt van haar moeder, reeds om die reden aanbestedingsplichtig is. Anders dan eerder in de Nederlandse rechtspraak wel is aangenomen mag de dochtermaatschappij voor wat betreft de vraag of er op haar een aanbestedingsplicht rust niet worden vereenzelvigd met haar moedermaatschappij, maar dient te worden beoordeeld of de dochtermaatschappij zelf voldoet aan de drie cumulatieve voorwaarden voor kwalificatie als publiekrechtelijke instelling (en daarmee als aanbestedende dienst). 